\title{
Long-term response of stratospheric ozone and temperature to solar variability
}

\author{
I. Bordi ${ }^{1,2}$, F. Berrilli ${ }^{3}$, and E. Pietropaolo ${ }^{4}$ \\ ${ }^{1}$ Department of Physics, Sapienza University of Rome, Rome, Italy \\ ${ }^{2}$ Research Centre CIABC, Sapienza University of Rome, Rome, Italy \\ ${ }^{3}$ Department of Physics, University of Rome Tor Vergata, Rome, Italy \\ ${ }^{4}$ Department of Physical and Chemical Sciences, University of L'Aquila, L'Aquila, Italy \\ Correspondence to: I. Bordi (isabella.bordi@roma1.infn.it)
}

Received: 14 September 2014 - Revised: 25 January 2015 - Accepted: 9 February 2015 - Published: 4 March 2015

\begin{abstract}
The long-term variability in stratospheric ozone mass mixing ratio $\left(\mathrm{O}_{3}\right)$ and temperature $(T)$ from 1979 to 2013 is investigated using the latest reanalysis product delivered by the European Centre for Medium-Range Weather Forecasts (ECMWF), i.e., ERA-Interim. Moreover, using the $\mathrm{Mg}$ II index time series for the same time period, the response of the stratosphere to the 11-year Schwabe solar cycle is investigated. Results reveal the following features: (i) upward (downward) trends characterize zonally averaged $\mathrm{O}_{3}$ anomalies in the upper (middle to lower stratosphere) stratosphere, while prevailing downward trends affect the $T$ field. Mg II index data exhibit a weaker 24th solar cycle (though not complete) when compared with the previous two; (ii) correlations between $\mathrm{O}_{3}$ and $\mathrm{Mg}$ II, $T$ and $\mathrm{Mg}$ II, and $\mathrm{O}_{3}$ and $T$ are consistent with photochemical reactions occurring in the stratosphere and large-scale transport; and (iii) wavelet cross-spectra between $\mathrm{O}_{3}$ and $\mathrm{Mg}$ II index show common power for the 11-year period, particularly in tropical regions around $30-50 \mathrm{hPa}$, and different relative phase in the upper and lower stratosphere. A comprehensive insight into the actual processes accounting for the observed correlation between ozone and solar UV variability would be gained from an improved bias correction of ozone measurements provided by different satellite instruments, and from the observations of the time behavior of the solar spectral irradiance.
\end{abstract}

Keywords. Meteorology and atmospheric dynamics (climatology)

\section{Introduction}

Variations in the solar irradiance represent one of the possible natural causes of climate change that is still poorly understood (see Gray et al., 2010, for a review). The Sun is the main source of energy for the Earth's system, and its variations may potentially influence the atmospheric dynamics. However, such an effect is controversial and tricky to prove, especially at tropospheric levels where the atmospheric variability is high. On the other hand, the amplitude of the change in the total solar irradiance (TSI) during the 11-year solar cycle (i.e., from solar magnetic activity minimum to maximum) is $\sim 0.1 \%$, corresponding to about $1 \mathrm{~W} \mathrm{~m}^{-2}$, causing a surface temperature increase of around $0.1 \mathrm{~K}$ due to direct radiative effects alone (e.g., Keckhut et al., 2005). Moreover, percent changes of TSI are not evenly distributed across the solar spectrum: they are concentrated in the ultraviolet (UV), so that wavelengths less than $400 \mathrm{~nm}$ contribute about $9 \%$ to the change, and about $32 \%$ of the radiation variation over a solar cycle occurs below $250 \mathrm{~nm}$ (Lean, 1989; Ermolli et al., 2013).

Thus, a way by which solar activity may influence the atmospheric circulation is through the stratosphere, in a topdown perspective (e.g., Gray et al., 2010; NRC, 2012). This occurs mainly through the absorption of UV solar radiation by ozone in the stratosphere (i.e., at midlatitudes, the altitudes between about $10-12$ and $50 \mathrm{~km}$ ) at wavelengths between 200 and $300 \mathrm{~nm}$, leading to the radiative heating observed at those levels, to positive temperature vertical gradients, and to increased static stability. In particular, solar UV photons have sufficient energy to give rise to chemical reac- 
tions able to create/destroy ozone (Hartly and Huggins bands at $200-350 \mathrm{~nm}$ ) or to dissociate oxygen diatomic molecules (Schuman-Runge bands at $100-200 \mathrm{~nm}$ ). The resulting latitudinal gradient of radiative heating drives the zonal circulation in the midlatitude upper stratosphere with maximum westerly amplitude during winter in both hemispheres. It is also known that the radiative equilibrium of the stratosphere plays an important role in determining the tropopause height condition for baroclinic neutrality (Bordi et al., 2002) or in modifying the properties of upward-propagating planetary waves (Charney and Drazin, 1961). Furthermore, it is worth recalling that ozone, although a minor component of the Earth's atmosphere (0.02-0.1 ppmv), plays a key role in the energy balance of the planet: it absorbs the UV solar radiation and acts as a greenhouse gas. In particular, with the spectral band centered at $9.6 \mu \mathrm{m}$, ozone contributes to the absorption of the thermal infrared radiation emitted by the Earth's surface, warming the lower stratosphere and cooling the upper stratosphere above $10 \mathrm{hPa}$ (see the spectral cooling rate profile in Clough and Iacono, 1995).

During the early 1990s, analyses of ozone and meteorological data began to suggest a substantial solar cycle variation in ozone and temperature in the stratosphere (e.g., Hood et al., 1993; Chandra and McPeters, 1994; Hood, 2004). More recently, the analysis of data from the Spectral Irradiance Monitor (SIM) instrument of the Solar Radiation and Climate Experiment (SORCE; Woods et al., 2000) showed that values of the solar spectral irradiance (SSI) increase with declining solar activity for wavelengths longer than $502 \mathrm{~nm}$, whereas they decrease for shorter wavelengths. This behavior suggests that SSI variability throughout the 11-year solar cycle could be significantly higher than thought until now, particularly in the UV spectral regions (e.g., Harder et al., 2009) with relevant effects on stratospheric ozone (Haigh et al., 2010). Moreover, Haigh et al. (2010) reported that spectral changes in UV during the decline since April 2004, which are 4 to 6 times larger than previously assumed, led to a significant decrease in stratospheric ozone for altitudes less than $45 \mathrm{~km}$, and an increase above that altitude.

The dependence of ozone to the solar cycle was supposed to be present from the analysis of total column ozone time series averaged over low latitudes, i.e., between $35^{\circ} \mathrm{S}$ and $35^{\circ} \mathrm{N}$ (see Soukharev and Hood, 2006, and references therein). The comparison of observations and various model outputs describing the complex ozone response to the UV solar spectral variation led to some discrepancy during the period 1979-2004 (e.g., Rozanov et al., 2004; Egorova et al., 2004), likely due to both the occurrence of two major volcanic eruptions (i.e., El Chichón in April 1982 and Pinatubo in June 1991) unfortunately close to the solar maxima of December 1979 and July 1989 (cycle 22 and 23), respectively, and the equatorial quasi-biennial oscillation (QBO) (Holton and Lindzen, 1972). Furthermore, solar energetic particles associated with space weather solar events and modulated by the solar activity can also enter into the Earth's atmosphere (e.g., Berrilli et al., 2014a), producing nitrogen oxides that can destroy ozone, changing the atmospheric chemistry and the radiative balance (e.g., Crutzen, 1974).

However, the global distribution of stratospheric ozone depends not only on the variability of solar energy but also on temperature, winds and pollutants (natural or humaninduced) through dynamical and chemical processes (for details, see Shepherd, 2008; McConnell and Jin, 2008). In particular, at high latitudes and low atmospheric heights, ozone abundances rise in winter due to transport and reduce in summer due to chemical destruction, whereas, in the middle stratosphere, the annual ozone fluctuation is mainly driven by the variability of the odd-oxygen $\left(\mathrm{O}\right.$ and $\left.\mathrm{O}_{3}\right)$ production rate. In the upper stratosphere, the annual ozone variation is related to the annual cycle of temperature (e.g., Perliski et al., 1989).

In the present work we investigate the connection between long-term variability of stratospheric ozone and temperature, at different latitudes and altitudes, in response to the UV solar variability associated with the 11-year cycle. For this purpose we took advantage of the availability of the reanalysis product ERA-Interim (hereafter ERA-I) delivered by the European Centre for Medium-Range Weather Forecasts (ECMWF), and the Mg II core-to-wing index by GOME, SCIAMACHY and GOME-2, both data sets extending from 1979 to present. The 35 years of data (1979-2013) cover three solar cycles and allowed us to provide an updated picture of the relationship between the 11-year solar variability and ozone and temperature in the stratosphere, which is the aim of the study. In particular, we analyze long-term trends in the time series (Sect. 3.1), linear correlations (Sect. 3.2), spectral periodicity and coherence (Sect. 3.3).

\section{Data and methods}

\subsection{ERA-Interim ozone and temperature data sets}

Ozone mass mixing ratio $\left(\mathrm{O}_{3}\right)$ and air temperature $(T)$ data used in the present study are taken from the latest global atmospheric reanalysis product ERA-I, which is delivered by the ECMWF and covers the period from 1979 to present (Simmons et al., 2007; Dee et al., 2011). The data set is produced with a sequential data assimilation scheme, advancing forward in time using 12-hourly analysis cycles. In each cycle, all available observations (in situ measurements, radiosondes, satellites, etc.) are combined with prior information from a forecast model to estimate the evolving state of the atmosphere (Dee et al., 2011). The four-dimensional variational (4D-Var) assimilation system used in ERA-I ensures the consistency between the analyzed variables and within the analyzed fields both in space and time for each analysis window. ERA-I improved on several deficiencies reported in the previous reanalysis, ERA-40, in particular the water cycle that was too wet in the tropics and breaks in time series 
of some variables that coincide with the introduction of satellites into the assimilation scheme (Poli et al., 2010).

A large variety of satellite ozone observations are used in ERA-I (see Dee et al., 2011, and their Fig. 15). It is worth noting that the major change in the ozone observing system occurred with the introduction of data from Global Ozone Monitoring Experiment (GOME) instrument on ERS-2 in 1996. The assimilation of GOME profiles has improved the quality of ERA-I ozone analyses relative to ERA-40, particularly in the troposphere and lower stratosphere. However, unrealistic temperature and wind changes were generated in a deep layer around the stratopause by the $4 \mathrm{D}$-Var in an attempt to accommodate observed local changes in ozone concentration mainly related to deficiencies in ozone observations (i.e., not adequate bias corrections for ozone data of different source). As a temporary solution, the sensitivity of mass and wind variables to ozone data is switched off and the ozone climatology is used in the radiation scheme (Dragani, 2011; Dee et al., 2011). Despite this shortcoming, the major features of the Brewer-Dobson circulation, including tropical upwelling into the stratosphere, and poleward and downward flow in the extratropics, are well reproduced by ERA-I (Seviour et al., 2012). The recent study by Dragani (2011) on the quality of ERA-I ozone data diagnosed an improvement with respect to ERA-40 and found mean residuals of about $\pm 10 \%$ compared to satellite observations.

In the present study, monthly means of daily means of $\mathrm{O}_{3}$ and $T$ from January 1979 to December 2013 at $0.75^{\circ}$ horizontal resolution and 11 vertical levels (from 100 to $1 \mathrm{hPa}$ ) are considered, and their annual means analyzed.

\subsection{Mg II proxy for UV solar irradiance variability data set}

TSI spaceborne records began in 1978 with satellite measurements of small changes in the solar constant due to the passage of large sunspots and plage regions across the solar surface (Willson et al., 1981). Nowadays, the variability of our star on all observed timescales, with amplitudes depending on the wavelength and timescale, is recognized (see the review by Solanki et al., 2013; Kopp, 2014). Magnetic features at the solar surface, modulated by photospheric multiscale flows, i.e., rotation, meridian flows, turbulent convection (e.g., Berrilli et al., 2013, 2014b), and global dynamo are the primary sources of variability of TSI and SSI, the bolometric and spectral quantity, respectively, of the radiative energy incident at the top of the Earth's atmosphere. Different features are associated with TSI and SSI variations at various timescales. Sunspots and faculae are responsible of large TSI variations (equal or greater than variations due to the 11-year cycle) on timescales ranging from a dozen hours to solar period (e.g., Frohlich, 2004; Solanki et al., 2013), while other magnetic or convective features are potentially connected to small-scale variability occurring on short timescales (e.g., Solanki et al., 2003; Viticchié et al., 2010). In 1978, unin- terrupted observations of solar UV variability began with the Nimbus-7 Solar Backscatter Ultraviolet (SBUV) instrument. Other spacecraft (SME, NOAA-9, NOAA-11, SOLSTICE) followed producing a data set extended over three solar cycles. In 2003 the Spectral Irradiance Monitor (SIM) experiment onboard the SORCE satellite measured the full solar spectral irradiance. Unfortunately, such measurements are relatively short in time to investigate the stratospheric ozone response to the 11-year solar cycle.

The Mg II index (core-to-wing ratio) is usually used as a proxy for the spectral solar irradiance variability from the UV to extreme UV associated with the 11-year solar cycle and solar rotation (27 days). It is constructed from the ratio of the irradiances of the highly variable Mg II $h$ and $k$ emission cores near $280 \mathrm{~nm}$ to that of the weakly variable nearby wings (Heath and Schlesinger, 1986). The index used for the present study is a composite provided by the University of Bremen derived from solar irradiances from GOME (1995-2011), SCIAMACHY (20022012) and GOME-2 (2007-present) aboard METOP-A and METOP-B (http://www.iup.uni-bremen.de/gome/gomemgii. $\mathrm{html})$. The annual and monthly mean time series of the $\mathrm{Mg}$ II index from 1979 to 2013 are taken into account for the present analysis. The Mg II core-to-wing ratio is commonly considered a good proxy of solar activity since it supplies a good estimate of UV irradiance variability (White et al., 1998; Viereck and Puga, 1999).

\subsection{Methods of analysis}

The linear trend in the time series of interest $\left(\mathrm{O}_{3}\right.$ and $\left.T\right)$ is here considered as a first-order indicator of long-term variability. It is computed by applying the least-squares method to fit the time series, while the non-parametric MannKendall test is used to assess its statistical significance. The test consists of comparing each value of the time series with the remaining in a sequential order and the probability level of significance of $95 \%$ is considered.

To investigate the relationship between the time series of interest $\left(\mathrm{O}_{3}\right.$ and $\left.T\right)$ and $\mathrm{Mg}$ II index at 11-year periodicity, we used the cross-spectral and coherence analysis derived from continuous wavelet transform (CWT). Torrence and Compo (1998) and Grinsted et al. (2004, henceforth GMJ04) provided detailed descriptions of such a method that is usually applied to analyze geophysical data series. Wavelet transform has advantages over the traditional Fourier transform for accurately decomposing finite, non-periodic and/or non-stationary time series (Sifuzzaman et al., 2009) like the ones we will show in Sect. 3.

In GMJ04 the CWT of a discrete sequence $x_{n}$ with uniform time step $\delta t$ is defined as the convolution of $x_{n}$ with a scaled and translated wavelet function $\psi_{0}(t)$ :

$$
W_{n}^{X}(s)=\sqrt{\frac{\delta t}{s}} \sum_{n^{\prime}=1}^{N} x_{n^{\prime}} \psi_{0}\left[\frac{\left(n^{\prime}-n\right) \delta t}{s}\right],
$$


where $s$ is the dilation parameter used to change the scale and $n$ is the translation parameter. In this work we used the Morlet wavelet, defined as

$\psi_{0}(\eta)=\pi^{-1 / 4} e^{i \omega_{0} \eta} e^{-\eta^{2} / 2}$,

where $\omega_{0}$ is a dimensionless frequency and $\eta$ is a dimensionless time. As reported in GMJ04, the Morlet wavelet (with $\omega_{0}=6$ ) is a good choice, since it provides a good balance between time and frequency localization; moreover, the wavelet Fourier period $\lambda_{\mathrm{wt}}$ is almost equal to the scale $s\left(\lambda_{\mathrm{wt}}=1.03 s\right)$.

The wavelet power is defined as $\left|W_{n}^{x}(s)\right|^{2}$, while the complex argument of $W_{n}^{x}(s)$ can be interpreted as the local phase. Since the CWT has edge artifacts due to the wavelet not being completely localized in time, it is useful to introduce a cone of influence (COI) in which edge effects cannot be ignored. Here, as reported in GMJ04, we take the COI as the area in which the wavelet power has dropped to $e^{-2}$ of the value at the edge.

Usually, statistical significance tests for wavelet power spectra are developed by deriving theoretical wavelet spectra for given background noise processes and using these to establish significance levels and confidence intervals. In the present paper, following Grinsted et al. (2004), the red noise and the $5 \%$ significance level are used.

The cross-wavelet transform (XWT) of two time series $x_{n}$ and $y_{n}$ is defined as $W^{x y}=W^{x} W^{y *}$, where the asterisk denotes complex conjugation. It examines the relationships between two time series by exposing their common power and relative phase in time and frequency space. The phase correlation between two time series is described by the phase angle and the statistical significance is estimated against a red-noise model.

Another useful measure is how coherent the cross-wavelet transform is in time-frequency space. Following Torrence and Webster (1998), the wavelet coherence of two time series is defined as

$R_{n}^{2}(s)=\frac{\left|S\left(s^{-1} W_{n}^{x y}(s)\right)\right|^{2}}{S\left(s^{-1}\left|W_{n}^{x}(s)\right|^{2}\right) S\left(s^{-1}\left|W_{n}^{y}(s)\right|^{2}\right)}$,

where $S$ is the smoothing operator taking into account both the smoothing along the wavelet scale and in time (Grinsted et al., 2004). Here we apply the XWT to the standardized monthly time series of $\mathrm{O}_{3}(T)$ and $\mathrm{Mg}$ II index by focusing on the 11-year periodicity. Wavelet coherence is then analyzed for those stratospheric regions showing maximum common power during that period.

\section{Results}

\subsection{Climatology and long-term trends}

Climatological means for the period 1979-2013 of the zonal mean stratospheric $\mathrm{O}_{3}$ mass mixing ratio and air temperature
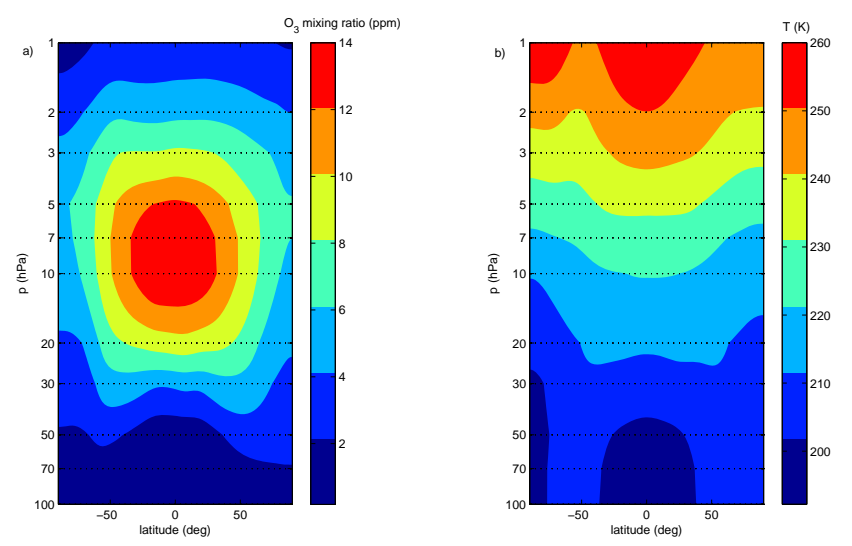

Figure 1. Climatological means for the period 1979-2013 of (a) zonal mean stratospheric $\mathrm{O}_{3}$ mass mixing ratio and (b) air temperature $T$. Units are ppm for $\mathrm{O}_{3}$ and $\mathrm{K}$ for $T$.

(latitude-pressure cross sections) are displayed in Fig. 1a and $b$, respectively. As expected, $\mathrm{O}_{3}$ is found to have maximum concentrations at about $10 \mathrm{hPa}(25-30 \mathrm{~km})$ in tropical regions, while minimum values characterize the lower stratosphere nearby the tropopause $(100 \mathrm{hPa})$. The resulting heating of the upper atmosphere, due to the absorption of solar ultraviolet radiation by ozone, leads to a temperature increase with height in the stratosphere with maximum value of about $260 \mathrm{~K}$ near the stratopause ( $1 \mathrm{hPa})$.

Trend analysis of annual ozone and temperature standardized anomalies (Fig. 2a, b) shows the following features: (i) $\mathrm{O}_{3}$ is characterized by upward trends above $7 \mathrm{hPa}$ (mostly statistically significant at the $95 \%$ confidence level) and downward trends below, with the exception of the tropical region around $30 \mathrm{hPa}$; (ii) $T$ reveals prevailing statistically significant downward trends at almost all levels and latitudes. The downward $\mathrm{O}_{3}$ trends in the middle-lower stratosphere are consistent with the depletion phenomenon observed since the late 1970s and mainly associated with the release of pollution containing the chemicals chlorine and bromine (Staehelin et al., 2001). The tendency towards an increasing ozone concentration in the upper stratosphere instead remains questionable because it is likely affected by the mentioned problem concerning the $\mathrm{O}_{3}$ data assimilation (i.e., the assimilation of GOME profiles since 1996; see Sect. 2.1). This problem clearly emerges from Fig. 3a, which shows the globalmean standardized anomaly time series of $\mathrm{O}_{3}$ at $2 \mathrm{hPa}$ (black line). The comparison with $T$ anomaly time series (Fig. 3a, red line) at the same level reveals an anti-correlation between the two variables, which will be discussed in the next subsection, and the signature of the two major volcanic eruptions, El Chichón in 1982 and Pinatubo in 1991.

The stratospheric cooling shown in Fig. $2 b$ is consistent with the theory on the thermal equilibrium of the stratosphere for increasing $\mathrm{CO}_{2}$ concentration and constant relative humidity (Manabe and Wetherald, 1967), also supported by ra- 

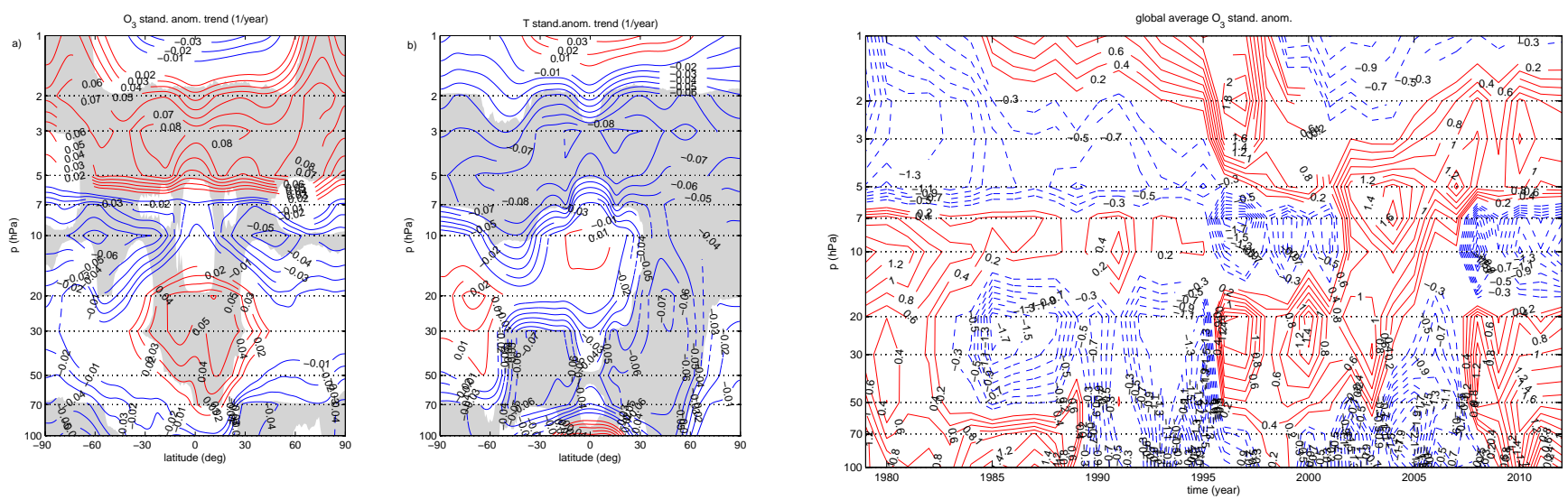

Figure 2. Latitude-pressure cross section of the slope of the linear trend for (a) $\mathrm{O}_{3}$ and (b) $T$ annual standardized anomaly. Shaded areas denote statistically significant trends at the $95 \%$ confidence level. Units for trends are per year.
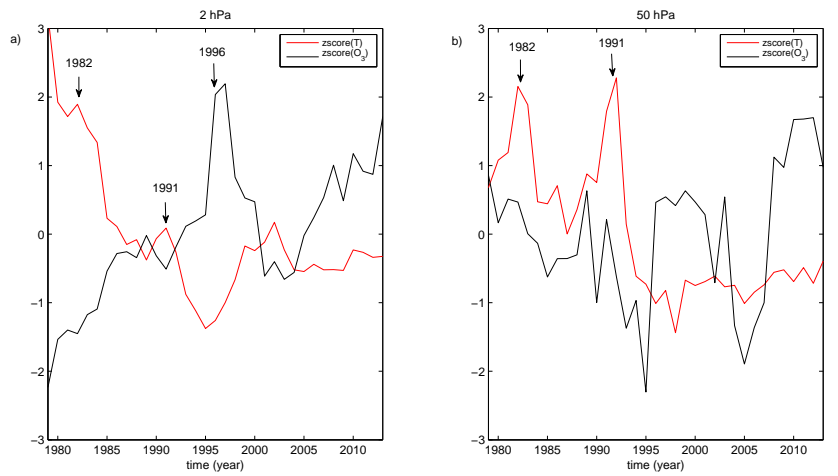

Figure 3. Time series of annual-mean, global-mean (area-weighted) standardized anomalies of $\mathrm{O}_{3}$ and $T$ ( $z$ scores) at (a) $2 \mathrm{hPa}$ and (b) $50 \mathrm{hPa}$. Arrows denote the starting year of GOME data assimilation into the reanalysis system (1996) and the major volcanic eruptions (El Chichón in 1982 and Pinatubo in 1991).

diosondes, satellites and lidar measurements (e.g., Thompson and Solomon, 2005; Randel et al., 2009). Also, it is thought that the lower stratospheric cooling is mostly driven by ozone depletion, with a possible (but uncertain) contribution from increases in stratospheric water vapor, at least during the period 1980-2000 as suggested by observations (Shine et al., 2003; Solomon et al., 2010). However, the major difficulties in developing an understanding of stratospheric temperature trends are uncertainties regarding the homogeneity of observational data, because the observing monitoring systems have been designed primarily to provide information for weather forecasting rather than for detection of long-term trends. Recent debates concern the reprocessing of satellite radiances that revealed the substantial cooling of the global lower stratosphere over 1979-2003 occurred in two pronounced step-like transitions (Ramaswamy et al., 2006; Thompson et al., 2012). These arose in the aftermath of two major volcanic eruptions (El Chichón and Pinatubo),

Figure 4. Time-pressure cross section of annual-mean, globalmean (area-weighted) standardized $\mathrm{O}_{3}$ anomaly (solid red lines for positive values and dashed blue lines for negative ones; zero line is excluded).

with each cooling transition being followed by a period of relatively steady temperatures. Although climate model simulations indicate that the stratospheric cooling is largely attributable to the combined effect of changes in both anthropogenic factors $\left(\mathrm{O}_{3}\right.$ depletion and increases in well-mixed greenhouse gases) and natural factors (solar irradiance variation and volcanic aerosols), discrepancies exist between observed and simulated global-mean stratospheric temperatures (Thompson et al., 2012). The ERA-I global-mean standardized $T$ anomaly at $50 \mathrm{hPa}$ (Fig. 3b, red line) shows such a behavior consistent with satellite measurements, with two transient warming events related to the volcanic eruptions followed by near-steady anomaly periods. The corresponding $\mathrm{O}_{3}$ anomaly (Fig. 3b, black line) has a decline during the first part of the record and a hint of recovery after 1996 (Yang et al., 2006).

To better describe how the recovery feature is captured by ERA-I reanalysis, the time-pressure cross section of annualmean, global-mean standardized $\mathrm{O}_{3}$ anomaly is shown in Fig. 4. As can be seen, positive anomalies characterize the stratospheric layers below $10 \mathrm{hPa}$ from 1996 onward, with an interruption around the year 2005. Thus, it seems that evidence for ozone recovery in the middle-lower stratosphere (about $90 \%$ of ozone in the Earth's atmosphere resides in the stratosphere) is masked by large long-term changes that dominate its current evolution, and a longer time is needed to corroborate the observed positive tendency.

In the upper stratosphere (1-5 hPa), Fig. 4 displays a positive anomaly in correspondence of GOME profiles assimilation in 1996, while at $10 \mathrm{hPa}$ positive anomalies occur during/after the solar maxima (i.e., 1981, 1989-1991, 20002002). The 11-year solar activity is well monitored by the Mg II index, whose monthly time series from January 1979 to December 2013 is reported in Fig. 5. It can be noted that, as predicted, the first maximum of the 24th cycle, which oc- 


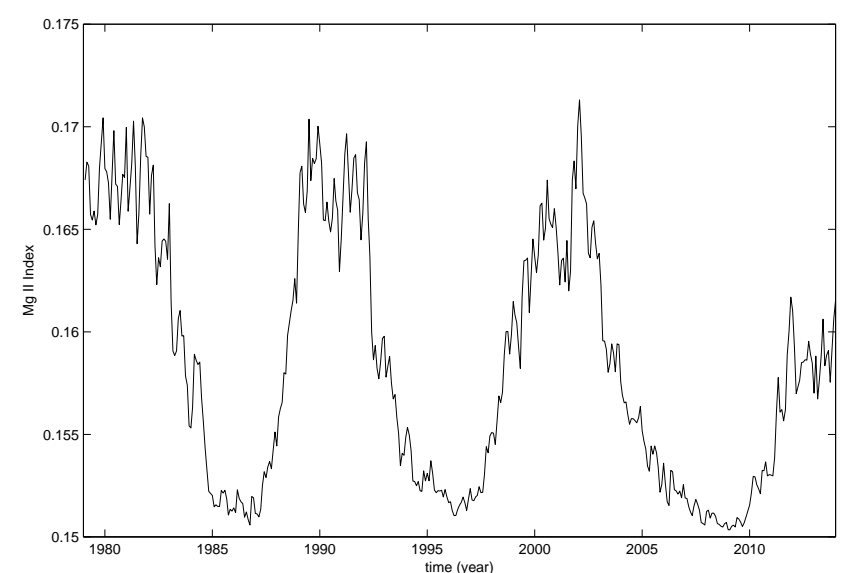

Figure 5. Monthly Mg II index time series from January 1979 to December 2013.

curred at the beginning of 2012 , is less intense than the previous three. The current (January 2015) observations and predictions of the solar activity makes the 24th cycle the smallest sunspot cycle since the 14 th cycle, with the first peak occurred on February 2012 and the second peak on April 2014 (http://solarscience.msfc.nasa.gov/predict.shtml). A correlation analysis between the solar index and ozone and temperature follows.

\subsection{Correlations}

Correlation maps between the annual, zonally averaged $\mathrm{O}_{3}$ and $\mathrm{Mg}$ II index, $T$ and $\mathrm{Mg} \mathrm{II}$ index, and $\mathrm{O}_{3}$ and $T$ are illustrated in Fig. 6. A positive correlation is found between $\mathrm{O}_{3}$ and $\mathrm{Mg}$ II index in the middle-lower stratosphere, and negative correlation above (Fig. 6a). It is worth noting that correlations of de-trended signals (not shown) confirm such tendencies.

The $\mathrm{O}_{3}$ decrease with increasing solar flux in the upper stratosphere and mesosphere is likely due to the increase in the rate of water photolysis, which leads to faster ozone destruction by $\mathrm{HO}_{\mathrm{x}}$ catalytic cycles (Egorova et al., 2005; Merkel et al., 2011).

The correlation between $T$ and $\mathrm{Mg}$ II index is positive at all latitudes and levels (Fig. 6b), suggesting a monotonically increasing relationship between temperature and solar activity mainly at tropical regions.

The correlation between $\mathrm{O}_{3}$ and $T$ is negative in the upper stratosphere (Fig. 6c), a feature that is reasonable because a higher temperature accelerates gas-phase chemical reactions, which destroy ozone molecules. On the other hand, the correlation is positive in the lower stratosphere, in contradiction with chemical kinetics, indicating that ozone in that region is governed mainly by transport (Sekiyama et al., 2006; Stolarski et al., 2012).
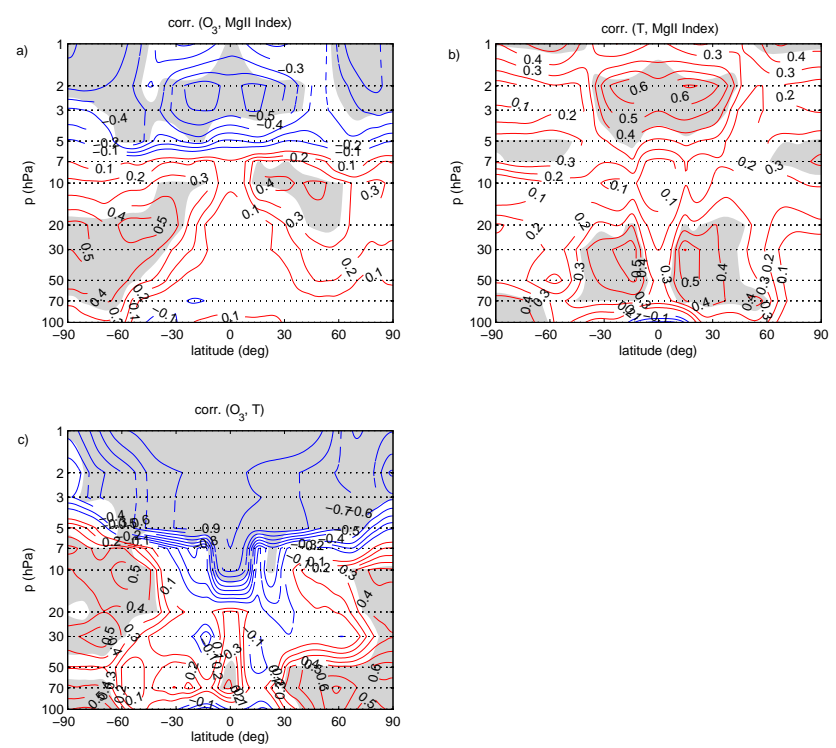

Figure 6. Maps of Pearson's linear correlation coefficients between (a) the annual, zonally averaged $\mathrm{O}_{3}$ and $\mathrm{Mg}$ II index, (b) $T$ and $\mathrm{Mg}$ II index, and (c) $\mathrm{O}_{3}$ and $T$. Shaded areas denote statistically significant correlations at the $95 \%$ level.

\subsection{Relationship with the 11-year solar cycle}

To isolate the signature of the 11-year solar cycle in stratospheric ozone mass mixing ratio and temperature, the wavelet cross-power spectral density (CPSD) between the two variables of interest and $\mathrm{Mg}$ II index is computed for each standardized anomaly time series at different latitudes and pressure levels. The latitude-pressure cross sections of CPSD for the 11-year period both for $\mathrm{O}_{3}$ and $T$ are displayed in Fig. 7.

For ozone (Fig. 7a), common high power is found in the lower stratosphere tropical regions $(30-60 \mathrm{hPa})$, and in the upper stratosphere at high latitudes in both hemispheres (around $3 \mathrm{hPa}$ ) and subtropics $(1-2 \mathrm{hPa}$ ). The dominant feature observed around $30-50 \mathrm{hPa}$ may be related to the connection between quasi-biennial oscillation (QBO) and solar activity. Some studies have in fact supported the solar influence on the lower stratosphere dynamics with the observed 11-year variation in the QBO in the stratospheric equatorial zonal winds (e.g., Labitzke, 2005; Soukharev and Hood, 2006; McCormack et al., 2007). Moreover, they showed that the combined effects of solar UV variations, the QBO and planetary wave forcing could provide a possible explanation for the 11-year ozone response in the tropical lower stratosphere, where the ozone distribution is largely controlled by transport.

For air temperature (Fig. 7b), common high power occurs mainly in the tropical regions both in the upper $(1-3 \mathrm{hPa})$ and in the lower stratosphere around $30 \mathrm{hPa}$, i.e., regions where the maximum correlation between $T$ and $\mathrm{Mg}$ II index has been observed (Fig. 6b). 

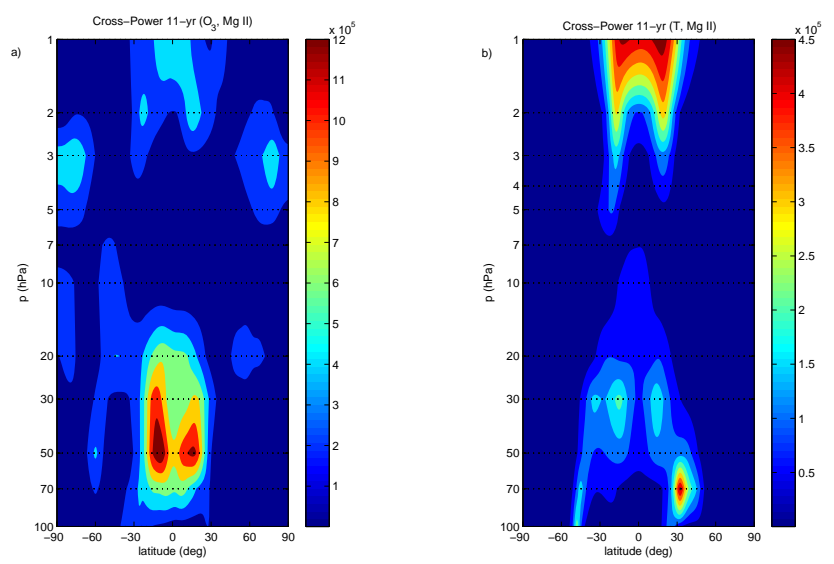

Figure 7. Latitude-pressure cross section of the wavelet crosspower spectral density (CPSD) for the 11-year period between (a) $\mathrm{O}_{3}$ and $\mathrm{Mg}$ II index and (b) $\mathrm{O}_{3}$ and $T$ monthly standardized anomaly time series.

Results of wavelet coherence between $\mathrm{O}_{3}(T)$ and $\mathrm{Mg}$ II index for the stratospheric regions with high values of CPSD at 11-year period are shown in Fig. 8 (Fig. 9). In the figures, thick contours identify the $5 \%$ significance level against red noise, while arrows denote the phase between the two signals. The upper panels in Fig. 8 refer to the latitude band $30^{\circ} \mathrm{S}-30^{\circ} \mathrm{N}$ at 30 and $1 \mathrm{hPa}$ : in both cases high values of coherence are found for the 11-year period, but while the signals are almost in phase in the lower level, they are out of phase in the upper level (phase locked around $180^{\circ}$ ). Moreover, it should be noted that the phase does not change over time, meaning that the two series should be physically related (Grinsted et al., 2004). The lower panels (Fig. 8c, d) show that, at $3 \mathrm{hPa}$, high latitudes, the two signals are coherent for the 11-year period with a phase locked between 180 and $270^{\circ}$. Thus, results are consistent with the correlation analysis (Fig. 6a) that showed negative correlation between $\mathrm{O}_{3}$ and $\mathrm{Mg}$ II index in the upper stratosphere and positive in the lower levels.

The analysis for $T$ (Fig. 9) shows that, in the tropical region $30^{\circ} \mathrm{S}-30^{\circ} \mathrm{N}$ at both pressure levels of 30 and $1 \mathrm{hPa}$, temperature and $\mathrm{Mg}$ II index are highly coherent at the 11year period and almost in phase, in agreement with Fig. 6b, which displays positive correlations on all pressure levels. It is worth noting that both Figs. 8 and 9 show features of high coherence for periods shorter than 11 years that, however, are localized in time and changing phase, making them less relevant from a physical point of view although they are statistically significant.
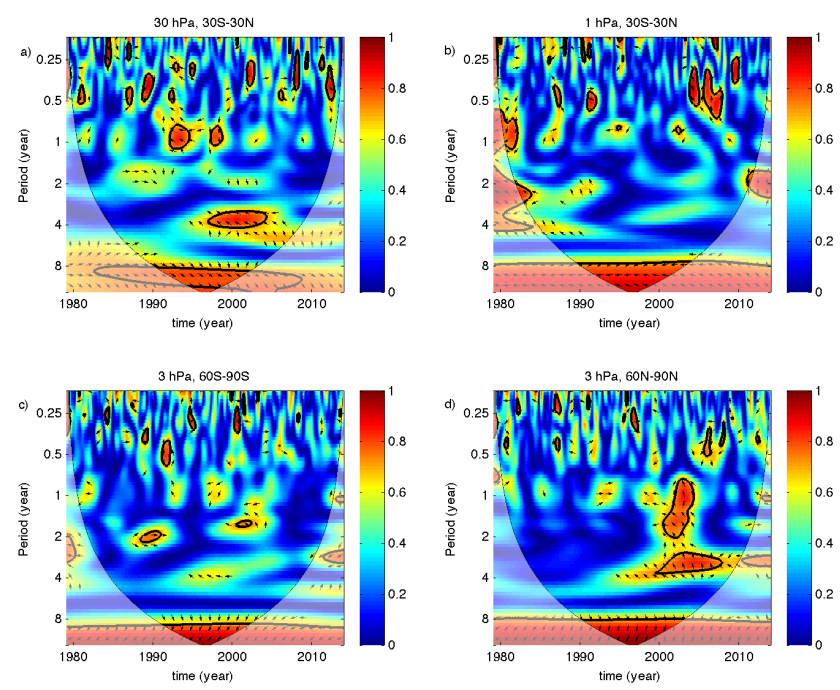

Figure 8. Wavelet coherence for the input signals $\mathrm{O}_{3}$ and $\mathrm{Mg}$ II index for selected vertical pressure levels and latitude bands: (a) $30 \mathrm{hPa}, 30^{\circ} \mathrm{S}-30^{\circ} \mathrm{N}$; (b) $1 \mathrm{hPa}, 30^{\circ} \mathrm{S}-30^{\circ} \mathrm{N}$; (c) $3 \mathrm{hPa}, 60^{\circ} \mathrm{S}-$ $90^{\circ} \mathrm{S}$; (d) $3 \mathrm{hPa}, 60^{\circ} \mathrm{N}-90^{\circ} \mathrm{N}$. Thick contours identify the $5 \%$ significance level against red noise, while arrows denote the phase between the two signals (in phase pointing eastward and out of phase pointing westward). The cone of influence (COI) where edge effects might distort the picture is shown as a lighter shade.

\section{Summary and conclusions}

The study provides an analysis of the interannual variability of stratospheric ozone and temperature during the last three decades (1979-2013) using the ECMWF reanalysis ERA-I. The relationship between $\mathrm{O}_{3}(T)$ and the 11-year solar cycle is investigated using the $\mathrm{Mg} \mathrm{II}$ index as a proxy for solar $\mathrm{UV}$ irradiance.

For a first-order indicator of the long-term variability we used the linear trend estimate in the time series, being aware of the limitations of such a method to draw any conclusion based only on the detected tendencies (e.g., the limited record length or the nonlinear nature of the time series). Results show that the zonally averaged $\mathrm{O}_{3}$ anomalies are characterized by upward (downward) trends in the upper (middle and lower) stratosphere (Fig. 2a). While the downward trends in the lower stratosphere are consistent with the ozone depletion observed since the late 1970s, the reliability of the upward trends in the upper stratosphere remain uncertain, likely affected by the problems related to the assimilation of $\mathrm{O}_{3}$ data into the reanalysis system (i.e., the assimilation of GOME profiles since 1996). As introduced in Sect. 2.1, in the reanalysis system, ozone is a prognostic variable of the forecast model and is analyzed with the other model state variables in 4D-Var analysis, which requires highly accurate ozone information. Unfortunately, the assimilation of ozone profiles into ERA-I caused systematic artificial changes in temperature and winds near the top of the model, where the flow 

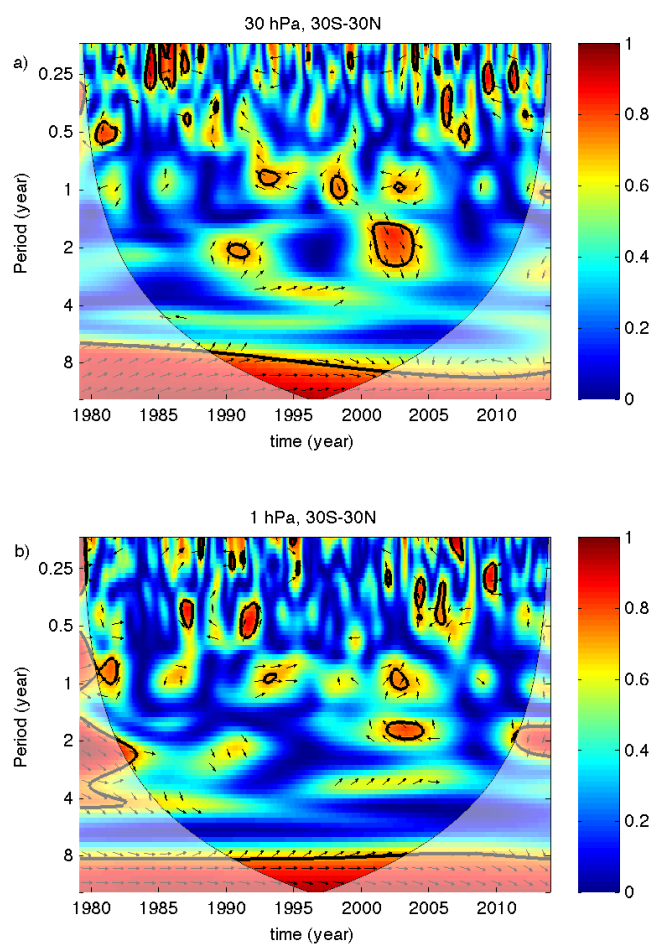

Figure 9. As in Fig. 8 but for the input signals $T$ and $\mathrm{Mg}$ II index: (a) $30 \mathrm{hPa}, 30^{\circ} \mathrm{S}-30^{\circ} \mathrm{N}$; (b) $1 \mathrm{hPa}, 30^{\circ} \mathrm{S}-30^{\circ} \mathrm{N}$. Thick contours identify the $5 \%$ significance level against red noise, while arrows denote the phase between the two signals (in phase pointing eastward and out of phase pointing westward). The cone of influence (COI) where edge effects might distort the picture is shown as a lighter shade.

is not well constrained by other observations. For this reason a temporary solution has been adopted by modifying the analysis scheme in order to prevent any direct influence of ozone observations on the dynamical fields. It is worth noting that, since such a problem cannot be fully addressed until adequate bias corrections for ozone data of different sources have been developed (hopefully in the next reanalysis system; Dragani and Dee, 2008; Dee et al., 2011), caution is required when ozone changes are estimated and interpreted. Artificial contributions to long-term trends or turning points may occur at upper stratospheric levels that likely cannot be properly corrected by the user of the reanalysis product.

The trend analysis of the $T$ field (Fig. 2b) reveals prevailing statistically significant downward trends at almost all levels and latitudes, which is the stratospheric cooling as predicted by the theory on the thermal equilibrium of the stratosphere for increasing $\mathrm{CO}_{2}$ concentration in the troposphere and constant relative humidity.

The analysis of correlations between $\mathrm{O}_{3}$ and $\mathrm{Mg}$ II, $T$ and $\mathrm{Mg}$ II, and $\mathrm{O}_{3}$ and $T$ are consistent with photochemical reactions occurring in the stratosphere and large-scale transport (Fig. 6).
Finally, the wavelet cross-spectra between $\mathrm{O}_{3}$ and $\mathrm{Mg}$ II index show common power at 11-year period, particularly in tropical regions at about $30-50 \mathrm{hPa}$ (Fig. 7a), and different relative phase in the upper and middle-lower stratosphere (Fig. 8). The feature observed around $30 \mathrm{hPa}$, where the ozone distribution is mainly controlled by transport, might be a signature of the connection between quasi-biennial oscillation (QBO) and solar activity. The same analysis for $T$ shows maximum common power in tropical regions at uppermost levels (Fig. 7b) and an in-phase relationship for the 11-year period (Fig. 9).

The overall results suggest the following remarks:

i. Although ozone has been observed over several decades with multiple instruments, combining the existing observations from many different sensors to produce consistent and homogeneous data suitable for scientific analyses remains a difficult task. Thus, an improved bias correction of ozone measurements provided by different satellite instruments would help in understanding the upward $\mathrm{O}_{3}$ trends detected above $7 \mathrm{hPa}$.

ii. The long-term trends discussed in the present paper, if confirmed by longer data records, should be analyzed in relation to the time behavior of the spectral UV solar irradiance (i.e., SORCE data) to understand the impact of the different UV spectral bands on the stratospheric ozone concentration.

iii. The application of the wavelet analysis showed that there are periodicities ranging from decadal to seasonal timescales embedded on the detected linear tendencies, suggesting the occurrence of nonlinear components in the observed changes. Additional analyses, preferably with longer data records, should be devoted to the analysis of trend patterns, nonlinear trends and seasonality, or long-term memory effects (for sample applications in the meteorological field, see Hannachi, 2007; Bordi et al., 2009, 2014, respectively).

iv. The spectral difference between the weak 24th solar maximum and the previous ones should also be investigated and the relative change in the stratospheric ozone and temperature quantified.

v. Finally, since a consensus regarding the impact of solar variability on cloud cover is far from being reached, it would be of interest to complement the present study with an analysis of the spatial and temporal variability of ERA-I cloud cover anomalies for the same time section.

These will be topics of future investigations. 
Acknowledgements. ERA-Interim reanalysis data were provided by the European Centre for Medium-Range Weather Forecasts (ECMWF), Reading, UK, through their website http://apps.ecmwf. int/datasets/. Mg II index data have been freely retrieved from the website of the Institute for Environmental Physics, University of Bremen, Germany, http://www.iup.uni-bremen.de/gome/ gomemgii.html (last access: 11 May 2014).

This work is partly supported through the Italian MIUR-PRIN grant 2012P2HRCR on "The active Sun and its effects on space and Earth climate" and the Space Weather Italian Community (SWICO) research program and benefits of the COST Action ES1005 TOSCA (http://www.tosca-cost.eu).

Topical Editor C. Jacobi thanks two anonymous referees for their help in evaluating this paper.

This paper is dedicated to Alfonso Sutera (1950-2013), who actively contributed with useful discussions and suggestions during the early stage of the study.

\section{References}

Berrilli, F., Scardigli, S., and Giordano, S.: Multiscale Magnetic Underdense Regions on the Solar Surface: Granular and Mesogranular Scales, Solar Phys., 282, 379-387, 2013.

Berrilli, F., Casolino, M., Del Moro, D., Di Fino, L., Larosa, M., Narici, L., Piazzesi, R., Picozza, P., Scardigli, S., Sparvoli, R., Stangalini, M., Zaconte, V.: The relativistic solar particle event of May 17th, 2012 observed on board the International Space Station, J. Space Weather Space Clim., 4, A16, doi:10.1051/swsc/2014014, 2014a.

Berrilli, F., Scardigli, S., and Del Moro, D.: Magnetic pattern at supergranulation scale: the Void Size Distribution, Astron. Astrophys., 568, A102, doi:10.1051/0004-6361/201424026, 2014 b.

Bordi, I., Dell' Aquila, A., Speranza, A., and Sutera, A.: Formula for a baroclinic adjustment theory of climate, Tellus A, 54, 260-272, 2002.

Bordi, I., Fraedrich, K., and Sutera, A.: Observed drought and wetness trends in Europe: an update, Hydrol. Earth Syst. Sci., 13, 1519-1530, doi:10.5194/hess-13-1519-2009, 2009.

Bordi, I., Fraedrich, K., Sutera, A., and Zhu, X.: Ground-based GPS measurements: time behavior from half-hour to years, Theor. Appl. Climatol., 115, 615-625, 2014.

Chandra, S. and McPeters, R. D.: The solar cycle variation of ozone in the stratosphere inferred from Nimbus 7 and NOAA 11 satellites, J. Geophys. Res., 99, 20665-20671, 1994.

Charney, J. G. and Drazin, P. G.: Propagation of planetary-scale disturbances from the lower into the upper atmosphere, J. Geophys. Res., 66, 83-109, 1961.

Clough, S. A. and Iacono, M. J.: Line-by-line calculation of atmospheric fluxes and cooling rates: 2. Application to carbon dioxide, ozone, methane, nitrous oxide and the halocarbons, J. Geophys. Res., 100, 16519-16535, 1995.

Crutzen, P. J.: A review of upper atmospheric photochemistry, Can. J. Chem., 52, 1569-1581, 1974.

Dee, D. P., Uppala, S. M., Simmons, A. J., Berrisford, P., Poli, P., and co-authors: the ERA-Interim reanalysis: configuration and performance of the data assimilation system, Q. J. Roy. Meteorol. Soc., 137, 553-597, 2011.
Dragani, R.: On the quality of the ERA-Interim ozone reanalyses: comparisons with satellite data, Q. J. Roy. Meteorol. Soc., 137, 1312-1326, 2011.

Dragani, R. and Dee, D. P.: Progress in ozone monitoring and assimilation, ECMWF Newsletter, 116, 35-42, 2008.

Egorova, T., Rozanov, E., Manzini, E., Haberreiter , M., Schmutz, W., Zubov, V., and Peter, T.: Chemical and dynamical response to the 11-year variability of the solar irradiance simulated with a chemistry-climate model, Geophys. Res. Lett., 31, L06119, doi:10.1029/2003GL019294, 2004.

Egorova, T., Rozanov, E., Zubov, V., Schmutz, W., and Peter, Th.: Influence of solar variability on chemical composition of the stratosphere and mesosphere simulated with a chemistry-climate model, Adv. Space. Res., 35, 451-457, 2005.

Ermolli, I., Matthes, K., Dudok de Wit, T., Krivova, N. A., Tourpali, K., Weber, M., Unruh, Y. C., Gray, L., Langematz, U., Pilewskie, P., Rozanov, E., Schmutz, W., Shapiro, A., Solanki, S. K., and Woods, T. N.: Recent variability of the solar spectral irradiance and its impact on climate modeling, Chem. Phys., 13, 39453977, 2013.

Frohlich, C.: Solar Irradiance Variability, in: Solar Variability and its effects on Climate, edited by: Pap, J. M. and Fox, P., Geoph. Monog. Series, 141, ISBN 0-87590-406-8, 2004.

Gray, L. J., Beer, J., Geller, M., Haigh, J. D., Lockwood, M., Matthes, K., Cubasch, U., Fleitmann, D., Harrison, G., Hood, L., Luterbacher, J., Meehl, G. A., Shindell, D., van Geel, B., and White, W.: Solar Influences on Climate, Rev. Geophys., 48, RG4001, doi:10.1029/2009RG000282, 2010.

Grinsted, A., Moore, J. C., and Jevrejeva, S.: Application of the cross wavelet transform and wavelet coherence to geophysical time series, Nonlinear Proc. Geoph., 11, 561-566, 2004.

Haigh, J. D., Winning, A. R., Toumi, R., and Harder, J. W.: An influence of solar spectral variations on radiative forcing of climate, Nature, 467, 696-699, 2010.

Hannachi, A.: Pattern hunting in climate: a new method for finding trends in gridded climate data, Int. J. Climatol., 27, 1-15, 2007.

Harder, J. W., Fontenla, J. M., Pilewskie, P., Richard, E. C., and Woods, T. N.: Trends in solar spectral irradiance variability in the visible and infrared, Geophys. Res. Lett., 36, L07801, doi:10.1029/2008GL036797, 2009.

Heath, D. F. and Schlesinger, B. M.: The Mg 280-nm doublet as a monitor of changes in solar ultraviolet irradiance, J. Geophys. Res., 91, 8672-8682, 1986.

Holton, J. R. and Lindzen, R. S.: An updated theory for the quasibiennial oscillation of the tropical stratosphere, J. Atmos. Sci., 29, 1076-1080, 1972.

Hood, L. L.: Effects of solar UV variability on the stratosphere, in: Solar Variability and its Effects on Climate, Geophys. Monogr. Ser., 141, edited by: Pap, J. M. and Fox, P., 283-303, AGU, Washington, D. C., 2004.

Hood, L. L., Jirikowic, J., and McCormack, J. P.: Quasi-decadal variability of the stratosphere: Influence of long-term solar ultraviolet variations, J. Atmos. Sci., 50, 3941-3958, 1993.

Keckhut, P., Cagnazzo, C., Chanin, M.-L., Claud, C., and Hauchecorne, A.: The 11-year solar-cycle effects on the temperature in the upper stratosphere and mesosphere. Part I: Assessment of observations, J. Atmos. Sol.-Terr. Phy., 67, 940-947, 2005. 
Kopp, G.: An assessment of the solar irradiance record for climate studies, J. Space Weather Space Clim., 4, A14, doi:10.1051/swsc/2014012, 2014.

Labitzke, K.: On the solar cycle-QBO relationship: A summary, J. Atmos. Sol.-Terr. Phy., 67, 45-54, 2005.

Lean, J. L.: Contribution of ultraviolet irradiance variations to changes in the sun's total irradiance, Science, 244, 187-200, 1989.

Manabe, S. and Wetherald, R. T.: Thermal equilibrium of the atmosphere with a given distribution of relative humidity, J. Atmos. Sci., 24, 241-259, 1967.

McConnell, J. C. and Jin, J.: Stratospheric ozone chemistry, Atmos. Ocean, 46, 69-92, 2008.

McCormack, J. P., Siskind, D. E., and Hood, L. L.: Solar-QBO interaction and its impact on stratospheric ozone in a zonally averaged photochemical transport model of the middle atmosphere, J. Geophys. Res., 112, D16109, doi:10.1029/2006JD008369, 2007.

Merkel, A. W., Harder, J. W., Marsh, D. R., Smith, A. K., Fontenla, J. M., and Woods, T. N.: The impact of solar spectral irradiance variability on middle atmospheric ozone, Geophys. Res. Lett., 38, L13802, doi:10.1029/2011GL047561, 2011.

NRC (National Research Council): The effects of solar variability on Earth's climate: A workshop report, National Academic Press, Washington, DC, 2012.

Perliski, L. M., Solomon, S., and London, J.: On the interpretation of seasonal variations of stratospheric ozone, Planet. Space Sci., 37, 1527-1538, 1989.

Poli, P., Healy, S. B., and Dee, D. P.: Assimilation of Global Positioning System radio occultation data in the ECMWF ERAInterim reanalysis, Q. J. Roy. Meteorol. Soc., 136, 1972-1990, 2010.

Ramaswamy, V., Schwarzkopf, M. D., Randel, W. J., Santer, B. D., Soden, B. J., and Stenchikov, G. L.: Anthropogenic and natural influences in the evolution of lower stratospheric cooling, Science, 311, 1138-1141, 2006.

Randel, W. J., Shine, K. P., Austin, J., Barnett, J., Claud, C., Gillett, N. P., Keckhut, P., Langematz, U., Lin, R., Long, C., Mears, C., Miller, A., Nash, J., Seidel, D. J., Thompson, D. W. J., Wu, F., and Yoden, S.: An update of observed stratospheric temperature trends, J. Geophys. Res., 114, D02107, doi:10.1029/2008JD010421, 2009.

Rozanov, E. V., Schlesinger, M. E., Egorova, T. A., Li, B., Andronova, N., and Zubov, V. A.: Atmospheric response to the observed increase of solar UV radiation from solar minimum to solar maximum simulated by the University of Illinois at Urbana-Champaign climate-chemistry model, J. Geophys. Res., 109, D01110, doi:10.1029/2003JD003796, 2004.

Sekiyama, T. T., Shibata, K., Deushi, M., Kodera, K., and Lean, J. L.: Stratospheric ozone variation induced by the 11-year solar cycle: recent 22-year simulation using 3-D chemical transport model with reanalysis data, Geophys. Res. Lett., 33, L17812, doi:10.1029/2006GL026711, 2006.

Seviour, W. J. M., Butchart, N., and Hardiman, S. C.: The BrewerDobson circulation inferred from ERA-Interim, Q. J. Roy. Meteorol. Soc., 138, 878-888, 2012.

Shepherd, T. G.: Dynamics, stratospheric ozone, and climate change, Atmos. Ocean, 46, 117-138, 2008.

Shine, K. P., Bourqui, M. S., de Forster, P. M., Hare, S. H. E., Langematz, U., Braesicke, P., Grewe, V., Ponater, M., Schnadt,
C., Smith, C. A., Haigh, J. D., Austin, J., Butchart, N., Shindell, D. T., Randel, W. J., Nagashima, T., Portmann, R. W., Solomon, S., Seidel, D. J., Lanzante, J., Klein, S., Ramaswamy, V., and Schwarzkopf M. D.: A comparison of model-simulated trends in stratospheric temperatures, Q. J. Roy. Meteorol. Soc., 129, 15651588, 2003.

Sifuzzaman, M., Islam, M. R., and Ali, M. Z.: Application of Wavelet Transform and its advantages compared to Fourier Transform, J. Phys. Sci., 13, 121-134, 2009.

Simmons, A., Uppala, S., Dee, D., and Kobayashi, S.: ERA-Interim: new ECMWF reanalysis products from 1989 onwards, ECMWF Newsletter No. 110, 25-35, 2007.

Solanki, S. K., Seleznyov, A. D., and Krivova, N. A.: Solar irradiance fluctuations on short timescales, ESA Publications Division, ISBN 92-9092-845-X, 2003, 285-288, 2003.

Solanki, S. K., Krivova, N. A., and Haigh, J. D.: Solar Irradiance Variability and Climate, Annu. Rev. Astron. Astr., 51, 311-351, 2013.

Solomon, S., Rosenlof, K. H., Portmann, R. W., Daniel, J. S., Davis, S. M., Sanford, T. J., and Plattner, G.-K.: Contributions of stratospheric water vapor to decadal changes in the rate of global warming, Science, 327, 1219-1223, 2010.

Soukharev, B. E. and Hood, L. L.: Solar cycle variation of stratospheric ozone: Multiple regression analysis of long-term satellite data sets and comparisons with models, J. Geophys. Res., 111, D20314, doi:10.1029/2006JD007107, 2006.

Staehelin, J., Harris, N. R. P., Appenzeller, C., and Eberhard, J.: Ozone trends: a review, Rev. Geophys., 39, 231-290, 2001.

Stolarski, R. S., Douglass, A. R., Remsberg, E. E., Livesey, N. J., and Gille, J. C.: Ozone temperature correlations in the upper stratosphere as a measure of chlorine content, J. Geophys. Res., 117, D10305, doi:10.1029/2012JD017456, 2012.

Thompson, D. W. J. and Solomon, S.: Recent stratospheric climate trends as evidenced in radiosonde data: global structure and tropospheric linkages, J. Climate, 18, 4785-4795, 2005.

Thompson, D. W. J., Seidel, D. J., Randel, W. J., Zou, C.-Z., Butler, A. H., Mears, C., Osso, A., Long, C., and Lin, R.: The mystery of recent stratospheric temperature trends, Nature, 491, 692-697, 2012.

Torrence, C. and Compo, G. P.: A practical guide to wavelet analysis, B. Am. Meteorol. Soc., 79, 61-78, 1998.

Torrence, C. and Webster, P. J.: The annual cycle of persistence in the El Niño-Southern Oscillation, Q. J. Roy. Meteorol. Soc., 124, 1985-2004, 1998.

Viereck, R. A. and Puga, L. C.: The NOAA Mg II core-to-wing solar index: Construction of a 20-year time series of chromospheric variability from multiple satellites, J. Geophys. Res., 104, 999510005, 1999.

Viticchié, B., Vantaggiato, M., Berrilli, F., Del Moro, D., Penza, V., Pietropaolo, E., and Rast, M.: Modeling the solar irradiance background via numerical simulation, Astrophys. Space Sci., 328, 39-42, 2010.

White, O. R., DeToma, G., Rottman, G. J., Woods, T. N., and Knapp, B. G.: Effect of Spectral Resolution on the Mg II Index as a Measure of Solar Variability, Solar Phys., 17, 89-103, 1998.

Willson, R. C., Gulkis, S., Janssen, M., Hudson, H. S., and Chapman, G. A.: Observations of solar irradiance variability, Science, 211, 700-702, 1981. 
Woods, T., Rottman, G., Harder, J., Lawrence, G., McClintock, B., Kopp, G., and Pankratz, C.: Overview of the EOS SORCE Mission, Proc. SPIE 4135, 192-203, 2000.
Yang, E.-S., Cunnold, D. M., Salawitch, R. J., McCormick, M. P., Russell III, J., Zawodny, J. M., Oltmans, S., and Newchurch, M. J.: Attribution of recovery in lower-stratospheric ozone, J. Geophys. Res., 111, D17309, doi:10.1029/2005JD006371, 2006. 